\title{
Early Detection Score of Preeclampsia Risk
}

\author{
Dhiana Setyorini $^{1}$, Budi Santoso ${ }^{2}$, Santi Martini ${ }^{3}$, Ernawati $^{2}$, Intim Cahyono ${ }^{1}$ \\ ${ }^{1}$ Department of Nursing, Health Polytechnic of Surabaya, ${ }^{2}$ Faculty of Medicine, Airlangga University, \\ ${ }^{3}$ Faculty of Public Health, Airlangga University
}

\begin{abstract}
Preeclampsia (PE) is a specific syndrome during pregnancy that only occurs after 20 week of pregnancy, signed by high blood pressure, edema, and protein in the urine. In the method of this present research, at the first stage, a case control design consisting of 704 pregnant women was analyzed using the multinomial logistic regression. At the second stage, scoring cards were set up based on the OR value and was continued with the "panel expert" attended by 10 informants to perfect the scores. At the third stage, a try-out was made using a cross sectional design for 110 pregnant women, and Mc Nemar Test was employed to analyze the results. The cross section, sensitivity, and specificity were analyzed with ROC curve. Significant variables of PE risks were history of DM, obesity, history of hypertension, age, PE descent, multigravida, and incomes. From the results of the analysis, the Mc Nemar test was $90.9 \%$, cross section was 7.5 , sensitivity was $96.8 \%$ and specificity was $79.7 \%$. Scoring card for the early detection of the PE risk is effective for detecting preeclampsia early.
\end{abstract}

Keywords: early detection, scoring card, preeclampsia

\section{Introduction}

Preeclampsia is a specific syndrome in the pregnancy that usually happens after the 20 week of pregnancy, signed by high blood pressure, edema, and protein in the urine. Preeclampsia is the main cause for $6-8 \%$ rate of maternal mortality or sickness and fetus all over the world $^{(1)}$. The Maternal Mortality Rate in Surabaya city in 2012 was caused among others by eclampsia $32.4 \%$, bleeding $8.1 \%$, sepsis or infection $5.4 \%$, long parturition $2.7 \%$ and others $51.4 \%{ }^{(2)}$. Using the early detection tool in the form of scoring card may enable the nurses and midwives to determine whether a pregnant women has preeclampsia risks or not. The aim of this present research is to order a scoring card for the early detection of the PE risk intended to prevent PE as an effort to reduce the MMR by improving the study on maternity nursing.

\section{Corresponding author:}

\section{Dhiana Setyorini}

E-mail: indhiatelu@gmail.com

Address: Pucang Jajar Tengah Street-56, Surabaya, Indonesia
The aim of this research is to order a scoring card for the early detection of the PE risk intended to prevent PE as an effort to reduce the MMR.

\section{Method}

This research was made in 4-stages: 1-Analyzing the risk factors of preeclampsia with observational research and the case control design analyzed with multinomial logistic regression for 704 pregnant women using quantitative design, 2-Setting up scoring card for the early detection off the PE risk, ordered based on the OR value obtained and continued with "panel expert" to perfect of the ordered score using the quantitative and qualitative design, 3-Trying out the scoring card for the early detection off the PE risk ordered in the population of pregnant women with cross sectional design for 110 pregnant women. At this stage, a statistical test with Mc Nemar test was made, meanwhile to determine the intersection, sensitivity and specificity were determined using the ROC curve with quantitative research design, 4-Giving recommendations for efforts made if the risks emerge. This research was conducted in dr.M.Soewandhie Hospital, Haji Hospital and dr.Soetomo hospital and some community health centers in Surabaya. Meanwhile the try-out of the scoring card 
was made in Haji Hospital and dr.Soewandie Hospital.

\section{Findings}

The variables influencing the preeclampsia incidence were income, parity, PE-E descents, age, history of hypertension, obesity, history of PE and DM. The accuracy of card was $90.9 \%$, the significance was 0.754 $(>0.05)$, meaning that the card is accurate and valid. The intersection of ROC curve was 7.5, so: 1) score $<7.5$ : PE happened, 2) score $\geq 7.5$ : high risk. The intersection of sensitivity and specificity test was 10 , the sensitivity was $96.8 \%$ (the card is able to make an early detection of the PE risk as accurate as $96.8 \%$ ). The specificity was $79.7 \%$ (the card may detect the pregnant women with no PE risk as accurately as $79.7 \%$ ). Therefore, this scoring card is able to prevent any mistake in diagnosis. From the classification of the scoring card for the early detection of the PE risk, two categories were obtained.

Figure-1. Dhiana Setyorini Score Card

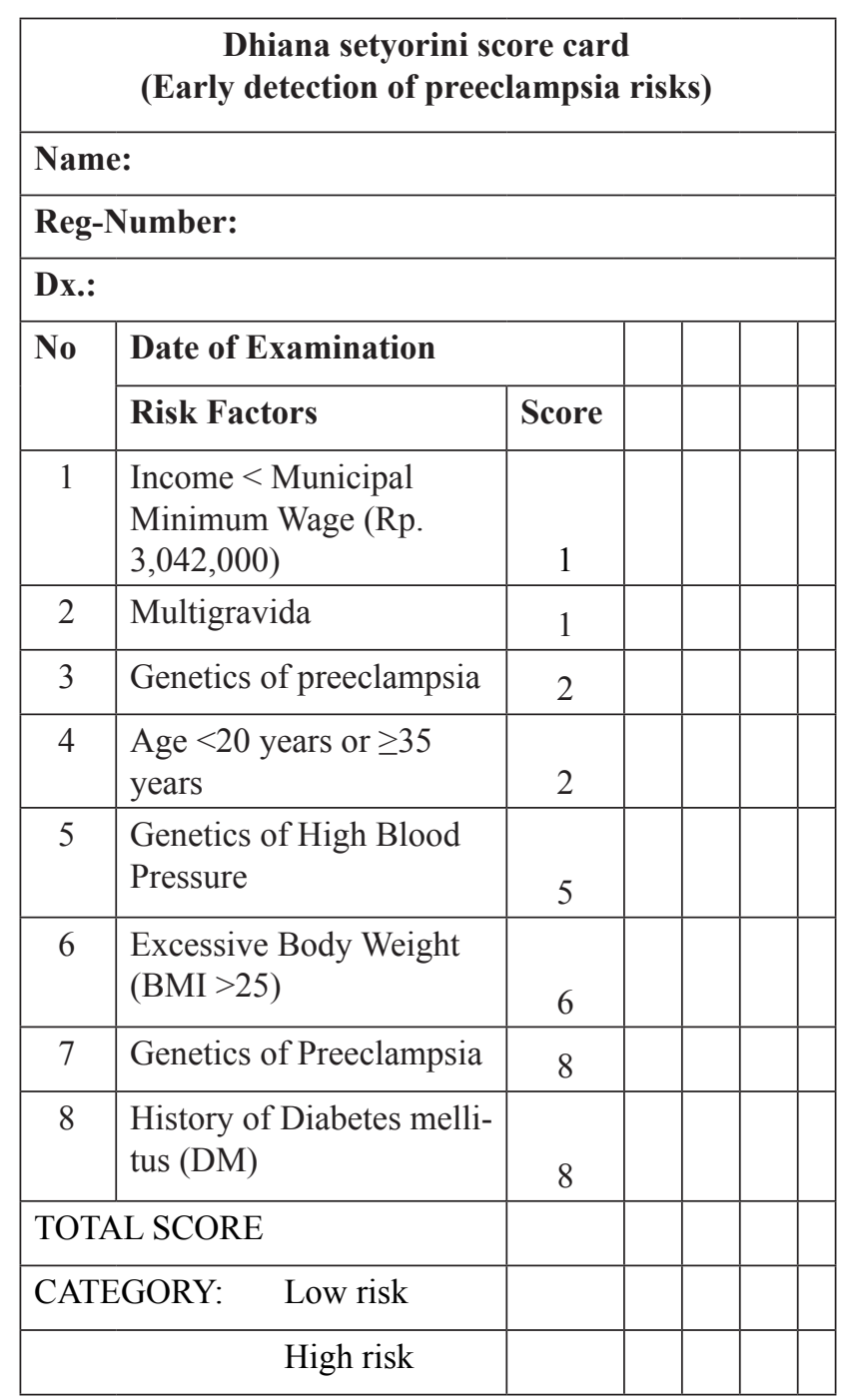

\begin{tabular}{|c|c|}
\hline NOTE: & $\begin{array}{l}\text { Low Risk, Score: }<7.5 \\
\text { High Risk, Score: } \geq 7.5\end{array}$ \\
\hline \multicolumn{2}{|c|}{ RECOMENDATION/SUGGESTION: } \\
\hline \multicolumn{2}{|c|}{ Facility and KIE } \\
\hline $\begin{array}{l}2 . \\
\text { Healtl }\end{array}$ & $\begin{array}{l}\text { High risk: Reference to the Second Level } \\
\text { Facility and KIE }\end{array}$ \\
\hline
\end{tabular}

\section{Discussion}

Low income has a close relationship with preeclampsia. High incidence of preeclampsia happens to Niger people living in South USA due to poverty and poor health treatment. This is related to the imbalanced nutritional intakes during pregnancy ${ }^{(3)}$.

Nutritional deficiency plays an important role in hypertension. The nutritional factor is related to hypertension through some mechanisms. ${ }^{(4)}$ Atherosclerosis is the main cause of hypertension. Exceeding fat consumption, deficiency of micro-nutrients such as vitamin-C, vitamin-E, Vitamin-B6 and minerals increase the homocysteine levels. High consumption of vitamin-D is the factor causing atherosclerosis because of calcium deposit that causes the damage of the elastic wall of the vascular ${ }^{(5)}$.

Pregnancy always has some preeclampsia risks. Parity is the number of children a Langelo woman bears $^{(6)}$. Preeclampsia may happen to multigravida, which is usually shown by a hypertension worsened by pregnancy. In multigravida, this disease is usually found in mothers with multi fetus and hydrop-fetalis pregnancies, mothers suffered from vascular diseases including chronics hypertension and diabetes mellitus or and kidney diseases. Mild-preeclampsia may happen due to high parity. This highly occurs to mothers with the ages of $>35$ years $^{(7)}$.

The preeclampsia incidence, according to the parity, mostly happens to multigravida namely $64,5 \%$ and scarcely occurs in primigravida, namely $35.5 \%$. This shows that there is a meaningful correlation between the parity and the preeclampsia incidence in pregnant women and statistically may be concluded with the $\mathrm{OR}=2.464$, meaning that multigravida has twice opportunities to have preeclampsia than primigravida ${ }^{(8)}$.

Preeclampsia was mostly found in multigravida where mild-preeclampsia was $70 \%$, severe-preeclampsia 
was $50.46 \%$ and superimposed-preeclampsia was $32 \%$. The present research results were not in line with the theory that preeclampsia often happens to primigravida. ${ }^{(9)}$ This is assumed to be related to the mother's first exposure to trofoblas from the fetus. ${ }^{(10)}$ A pregnant woman will give a protection effect to the preeclampsia in the next pregnancy, while a woman doing an abortion will have a weak protection. This is related to the immunology mechanism to the exposure of the fetus's antigen belonging to the mother during her first pregnancy ${ }^{(11)}$. Immunity is obtained when the next pregnancy happens with the same husband. Although the risk to preeclampsia is lower, the protection effect to the multipara will lose if she changes her husband, this is assumed to be caused by the exposure of the antigen to the new sperm ${ }^{(10)}$.

It is possible that preeclampsia is inherited, especially for the first pregnancy because the incidents of preeclampsia form girls are higher in number compared with those of daughters in law. It is called gen recessive ${ }^{(12)}$.

This research result was in line with a theory that a pregnant mother with preeclampsia history tends to be inherited, preeclampsia as a disease inherited to daughters or sisters. Moreover, this was also in line with another research that there is a meaningful correlation between the history of preeclampsia heredity and preeclampsia incidence ${ }^{(13)}$.

The number of mothers suffering from preeclampsia was those at the age groups of $<20$ years and $\geq 35$ and the number was higher than normal pregnancy. This is due to the fact that very early age makes them not be ready to be pregnant so that she might become anxious. Women $>35$ years with degenerative diseases often happened to suffer from preeclampsia.

Younger mothers have higher risks to suffer from preeclampsia where the incident mostly happens to those at the ages of 20-25 years. This incidence will increase in number for those with the ages of 15 and 35 years. These you women psychically are not ready to be pregnant, so that they are shy to go out of the homes and to go the doctor to have their pregnancy to be examined. Young mothers with pregnancy often show irregular blood pressure and do not pay attention to the pregnancy and this condition is supported by being their psychical unreadiness to be pregnant where it is this condition that makes their blood pressure increase and the hypertension $\operatorname{occurs}^{(3)}$.

Women at the age of $\geq 35$ years are susceptible to suffer from diseases in the forms of hypertension and eclampsia because some changes happen to the womb and the birth canal is inelastic. Higher blood-pressure often rises in line with the increase of the age. Therefore, at the age or 35 years or more the risk of preeclampsia tends to be higher ${ }^{(14)}$.

In the bodies of mothers at the age of $\geq 35$ years, some changes due to organs have occurred. Some physical conditions as a whole such as the degradations of the kidneys and livers, the increase in the blood pressures and diabetes mellitus also have also be lower. This condition causes the possibility to have preeclampsia during pregnancy to be higher. At the age of $\geq 35$ years, women face higher risks in pregnancy either from the pregnancy or the childbirth since at the age, women might have symptoms of blood clots where the risks are miscarriage, preeclampsia-eclampsia, congenital defects and $\mathrm{LBW}^{(14)}$.

The history of hypertension is the risk factor of the incidence of severe-preeclampsia ${ }^{(15)}$. In Soewondo Hospital, it can be concluded that there was a significant correlation between the history of hypertension and preeclampsia/eclampsia incidences. The pregnant women with hypertension had 2.98 times risks with those without hypertension ${ }^{(13)}$.

From the third of women with high blood pressures after 30 weeks pregnancy without any other symptoms, $20 \%$ showed increase in blood pressures and could be accompanied with one or more symptoms of preeclampsia such as edema, proteinuria, headache, epigastrium pain, puke, or visus disorder (superimposedpreeclampsia), even eclampsia and brain blooding may happened. Women with history of hypertension has higher risks to have severe-preeclampsia/eclampsia with the increase of $25 \%{ }^{(16),(17)}$.

The increase of body weight influences the cause of preeclampsia in pregnant women. The women with BMI of $>30$ at the beginning of pregnancy tend to suffer from preeclampsia. It is estimated that the increase of preeclampsia risks before pregnancy according to Robson is 2.5 times, whereas when the examination is made during the antenatal period the increase of the preeclampsia risks is 1.5 times. The increase of the body weight of the preeclampsia women deals with the peak of the inflammation response which is related to 
obesity. This preeclampsia condition happens due to less blood stream to organs of either the mother or the fetus. There are factors influencing preeclampsia: hidramnion, multiple pregnancy, hydatidiform mole, and diseases accompanying pregnancy: DM, obesity, and $>35$ years of age. Pregnant women with overweight tend to have diseases due obesity because it will influence the metabolism process in the body, the breath process, and all working body organs ${ }^{(18)}$.

This result is in line with the result of researches made by Clausen in Norway and Asim in Kacachi Hospital Pakistan that the obesity in pregnant women may increase the risk of hypertension in the pregnancy that would develop from severe-preeclampsia into eclampsia. This condition will increase various pregnancy complications that may result in the emergency condition of the mother and the fetus and also in increasing the death risk, either during maternal or prenatal period ${ }^{(19)}$.

There is a significant effect between the number of pregnancy and the increase of body weight and the eclampsia incidence. From the association test, it was found that the number of pregnancy and the increase of body weight is the risk factor to eclampsia incidence ${ }^{(20)}$.

Obesity not only cause high cholesterol in the blood and also the heart to work harder because the amount of the blood in the body increases around $15 \%$ from the body weight. Therefore, when someone is fatter, it means that the amount of one's blood also increases, meaning that this may result in the heart to pump the blood more hardly where it may contribute to the preeclampsia incidence ${ }^{(13)}$.

Preeclampsia incidence might be based on the single recessive gene or dominant gen with imperfect penetration. The penetration might be depended upon the genotype of the fetus ${ }^{(21)}$. The history of preeclampsia in the previous preeclampsia pregnancy is one of the factors supporting the preeclampsia in pregnancy ${ }^{(22)}$.

A mother who had preeclampsia in her previous pregnancy or who had suffered from hypertension for about 4 years or more has a greater risk to experience preeclampsia in pregnancy ${ }^{(17)}$.

A pregnant woman with the history of preeclampsia has a tendency to experience a severe-preeclampsia and it is stated that there is a correlation between the history of preeclampsia in pregnancy and the preeclampsia incidence $^{(13)}$.
The $50.9 \%$ of heavy preeclampsia happened to women with the history of preeclampsia. The history of preeclampsia is a good predisposition factor to determine whether a woman might experience preeclampsia ${ }^{(16),(20)}$.

The preeclampsia incidence among the women suffered from diabetes mellitus is $9.9 \%$, while that among non diabetes mellitus sufferer is $4 \%$. This percentage increases $30 \%$ to the women with DM-type-1 with hypertension. But, the evidence of the preeclampsia incidence to women with abnormal glucose tolerance and gestational diabetes are opposite one and another. ${ }^{(23)}$

Diabetes mellitus in pregnancy is the disease of metabolism abnormality where the body of the sufferer cannot automatically control the level of glucose in his or her blood. The sufferer cannot produce enough insulin and this results in excessive glucose in the body ${ }^{(24)}$.

Gestational diabetes mellitus is metabolic disorder in light pregnancy, but light hyperglycemia may hinder a pregnant women in the form of preeclampsia. This result supported the previous research result that one of the factors causing preeclampsia is the pregnant woman with $\mathrm{DM}^{(25) \text {. }}$

\section{Conclusion}

1) The PE risk covers (a) the reproduction factor which is the PE risk factors, namely: age $<20$ years and $\geq 30$ years, multigravida, and PE-E descendants, (b) the health status factor of which the PE risk factors are as follows" hypertension, PE-E and DM stories and obesity, and (c) social economic factor, where the PE factor is low income (lower than the average minimum wage), 2) this scoring card is able to make early detection of PE with the accuracy of $90.9 \%$ than the gold standard, and with the sensitivity of $96.8 \%$ d the specificity of $79.7 \%$.

\section{Conflict of Interest- No}

Source of Funding-Authors

Ethical Clearance- Yes

\section{References}

1. Charles JL, Murat B, Umit KA, Maritza M, Irina B, Catalin B, et al. Preeclampsia-Releted Inflammetory Cytokines Regulete Interleukin-6 Expression in Human Decidual Cells. The American Journal of Pathology. 2008;172:1571-1579. 
2. Dinkes-Jatim. Health Profile of East Java. Surabaya: Dinkes-Jatim; 2013.

3. Duenhoelter, Bersinger A., Groome N, Muttukrishna S. Pregnancy-Associated and Placental Proteins in The Placental Tissue of Normal Pregnant Women and Patients with Pre-Eclampsia at Term. Eur.J.Endocrinol. 2002;147:785-793.

4. Angsar M. Obstetrics. Jakarta: Bina-PustakaSarwono; 2010.

5. Jeffrey S, Gilbert, Michael J, Ryan, Babbette B, LaMarca, et al. Pathophysiology of Hypertension During Preeclampsia: Linking Placental Ischemia with Endothelial Dysfunction. Am.J.Physiol Heart Circ Physiol. 2008;294:541-550.

6. Langelo L, Arsin A, Russeng. Risk Factors of Preeclampsia Incident in Siti Fatimah Hospital. UNHAS; 2013.

7. Cunningham F, Gary, Norman F, Gant, Kenneth $\mathrm{J}$, Leveno, et al. Pregnancy Hypertension on Obstetrics. New-York: McGraw-Hill-Companies; 2010.

8. Carlo, Chappell L, Seed P, Briley A. Effect of Antioxidants on the Occurrence of Preeclampsia in Women at Increased Risk; A Randomised Trial. The Journal of Clinical Investigation. 2008;107:255-63.

9. Harrison KA. Risk Factor for Pre-Eclampsia at Antenatal Booking: Sstematic Rewiew of Controled Studies. BMJ. 1985;330-337.

10. Sibai BM. Maternal Fetal Medicine, Evaluation and Management of Severe Pre-eclampsia Before 34 Weeks's Gestation. American Journal of Obstetry and Gynecology. 2011;7:7-17.

11. Spellacy. Survey of Correlation Between Preeclampsi an Season and Some of its Risk Factor in Pregnancy Women. Journal Women's Health Care. 2012;1:3-11.

12. Manuaba IB. Obstetrics, Gynecology and Family Planning for Midwifery Education. Jakarta: EGC; 2010.

13. Rozikhan. Risk Factors for the Occurrence of Severe Preeclampsia at Soewandi Hospital, Kendal. Thesis. 2007.
14. Sri YU. Risk Factors Associated with Severe Preeclampsia in Pregnant Women in Raden Mattaher Hospital, Jambi in 2007. Jur.Ilm.Uni. Batanghari-Jambi. 2007;8-12.

15. Agudelo J, Belizan J. Risk Factors for PreEclampsia in Large Cohort of Latin American and Caribbean Women. BJOG. 2001;107:75-83.

16. Derek LJ, Daikoku T, Matsumoto H, Gupta RA, Das SK, Gassmann M, et al. Expression of HypoxiaInducible Factors in The Periimplantation Mouse Uterus is Regulated in a Cell-Specific and Ovarian Steroid Hormone-Dependent Manner. Evidence for Differential Function of Hifs During Early Pregnancy. Journal-Biol-Chem. 2003;278:76837691.

17. Cunningham F, Gary, Norman F, Gant, Kenneth J, Leveno, et al. Obstetrics Williams. Jakarta: EGC; 2006.

18. Manuaba IB. Obstetrics-Gynecology Emergency and Social Obstetrics-Gynecology for Midwife Professionals. Jakarta: EGC; 2008.

19. Clausen T, Oyen N, Henriksen T. Pregnancy Complications by Overweight and Residential Area: A Prospective Study of an Urban Norwegian Cohort. Acta Obstet Gynecol Scand. 2006;85:526533.

20. Luealon, Phupong P. Risk Factors of Preeclampsia in Thai Women. Journal of The Medical Association of Thailand. 2010;93(6):661-666.

21. Haryono HR. Efforts to Reduce Maternal Morbidity and Mortality of Preeclampsia/Eclampsia. Medan: FK-USU; 2006.

22. Mochtar R. Obstetrics Synopsis. Jakarta: EGC; 2008.

23. Roxanna. Assesment of Risk for The Development of Pre-Eclampsi by Maternal Characteristic and Uterine Artery Doppler. BJOG: International Journal of Obstetrics and Gynecology. 2010;112:703-709.

24. Rukiyah AY. Midwifery Care-IV (Midwifery Pathology). Jakarta: Trans-Info-Media; 2010.

25. Setyorini D. "Normal and Complicated" Maternal Care. Jur.Kep. 2012;3(2):35-41. 